\title{
CONTROL APPROACHES FOR TEMPERING MACHINE TOOL FRAMES WITH MULTIPLE FLUID CHANNELS AND LIMITED, JOINTLY USED ACTUATING VARIABLE
}

\author{
S. Mater ${ }^{1}$, A. Hellmich ${ }^{1 *}$, J. Popken ${ }^{2}$, S. Ihlenfeldt ${ }^{1,2}$ \\ ${ }^{1}$ Fraunhofer Institute for Machine Tools and Forming Technology IWU, Department Cyber-Physical Production \\ Systems, Dresden, Germany \\ ${ }^{2}$ TU Dresden, Institute of Mechatronic Engineering, Dresden, Germany \\ *Corresponding author; e-mail: arvid.hellmich@iwu.fraunhofer.de
}

\begin{abstract}
Nowadays, the thermo-energetic design of a machine tool also includes the thermal stabilization of its machine components. In the past, thermal stability was irrefutable connected to minimizing the temperature gradient of machine tools by air conditioning the entire machine or even the factory hall. Today, thermal stability also defines minimal inhomogeneities in the temperature field of the machine tool due to higher energy efficiency requirements.

Fluidic tempering systems of machine components offer considerable potential concerning the minimization of thermo-elastic displacements with acceptable energy demand. Hence, intelligent algorithms are required to combine tolerable geometric deviations with minimal energy effort. The scope of this paper is the integration of a demand-oriented fluidic temperature control system into a machine bed. The resulting multi-input-multi-output (MIMO) systems and varying boundary conditions are challenges, which are addressed. Therefore the paper compares two control approaches, a decentralized single-loop control and a multi-loop control by decoupling the control loops and especially focus on the distribution of the jointly used actuating variable, combined with the variation of different boundary conditions.
\end{abstract}

\section{Keywords:}

Machine tool; machine tool frame; fluidic temperature control system; control strategy; limited actuating variable

\section{INTRODUCTION}

In machine tools, positioning errors of the tool center point lead to inaccurate work pieces. Due to better correction and compensation methods for static, dynamic and geometrickinematic errors on machine tools, the share of thermally induced errors in the total error has increased in recent years [Großmann 2016].

In addition, more efficient machine tools often require more power input, which, in turn, leads to higher energy consumption, resulting in even higher heat output due to the correlation of energy loss and energy consumption. These losses however increase the influence of thermal problems even further [Wegener 2014]. Due to generally unavoidable heat sources in machine tools, it is a highly relevant research question to control the thermal load as precisely as possible [Putz 2018]

Today, in almost all machine tools cooling systems are already integrated, which enable a temperature control of the machine components [Brecher 2017]. However, limited coolant supplies, various categories of disturbance variables and often the large number of fluid channels result in a challenging control problem. This is why many cooling mechanisms are operated permanently or with two-point controllers, although this is inefficient and tends to be inaccurate [Augenstein 2012].
Thus, it is necessary to find demand-oriented and energyefficient control strategies that take these factors into account. Accordingly, the goal of the present work is the development and comparison of different control strategies for the temperature control of a machine tool frame. The presented research was carried out within the CRC/TR96 on the thermo-energetic design of machine tools with the aim of achieving a high level of working accuracy with a reasonable energy input. Based on a simplified model of a frame structure with three fluid channels, two control strategies for the present MIMO system will be worked out, which are then implemented and investigated in a simulation with Matlab/Simulink ${ }^{\odot}$. Subsequently, the results are processed and evaluated, from which recommendations for the selection of a suitable control strategy for temperature control are to be formulated.

\section{STATE OF THE ART}

\subsection{Thermal issues in machine tools}

The quality of a product depends significantly on the working accuracy and performance of the machine tool and its interaction with the environment [Ess 2012]. The static, dynamic, geometric-kinematic and thermoelastic deformation behaviour determine the working accuracy of the production system [Brecher 2017]. 


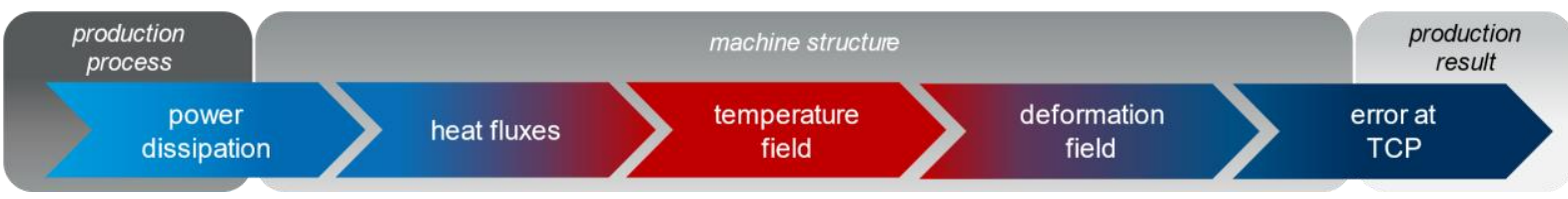

Fig. 1 : Thermo-elastic functional chain, influencing the temperature field [Großmann 2015]

In order to meet the demand for more precision and efficiency in production, it is essential to minimize product defects caused by thermoelastic deformation. To this end, individual machine components, e.g. drives, are being further developed with the aim of increasing power density. Often the higher power densities are achieved with a higher energy input, which also results in higher power losses. These then lead to local heat input or heat flows within the component [Neugebauer 2013]. Fig. 1 shows the thermoelastic functional chain that illustrates the course from power losses resulting from the process, fluid, drive and motion systems, to motion errors at the tool centre point (TCP). Heat is transferred within the machine structure and to the environment, from which temperature and deformation fields are created via heat fluxes [Großmann 2015].

Extensive experimental work has shown that $75 \%$ of the geometric deviations are caused by thermal influences [Mayr 2012]. Product defects, caused by the processes along the thermo-elastic functional chain, therefore represent a challenge, "(...) since there are large time constants between the effect - temperature-related elongation - and the cause - heat flow or power loss" [Großmann 2015]. The described change in the demands on production systems is accompanied by the temporal and spatial change in the thermal character of machine tools from stationary, dormant to transient, and moving, which is caused by increased heat input and strongly varying time regimes for the movement and loading processes. In the past, it was considered irrefutable to eliminate thermal influences by air-conditioning the entire machine, but today the aim is increasingly to minimize temperature gradients and the resulting deformations. To this end, there is a need to find holistic mechatronic solutions that include a thermoenergetic design of the machine tool, energy-efficient drives and machine components, and model-based compensation procedures for the temperature gradient [Wegener 2014].

For the implementation of an intelligent, demand-oriented and thus energy-efficient temperature control of individual components of a machine tool, the creation of virtual models that can depict and predict the temperature behaviour of the individual components is essential [Ramesh 2003] [Ihlenfeldt 2017] [Liu 2019].

\subsection{Temperature control in machine tools}

Various sources [Smith 2009] [Regel 2018] [Mori 2019] indicate that the integration of cooling systems in individual machine components or a holistic air conditioning system has proven to be the current state of the art. On the one hand, systems are used to track permanent cooling without temperature control to a setpoint value.

With a view to the future and the urge for resource efficiency and sustainability, this method cannot be regarded as decent. On the other hand, cooling systems with a two-point control are integrated. Such a control system is both inexpensive and simple to set up, but in any case, a hysteresis occurs. If this tolerance is chosen to be large, inaccuracies occur which cannot fulfil the accuracy requirements of a temperature control. If the chosen hysteresis is very small, a high wear and tear of the cooling system components occurs, because of the high switching frequency of the control.
Therefore, a current research focus is to find intelligent approaches for the temperature control of machine tool components. In general, the aim of a temperature control is a fast adjustment of the controlled variable to the set point. This often requires a large amplitude of the actuating variable, which is limited by physical boundary conditions in almost all technical applications. If this limitation affects the time response of the actuating variable, a significant influence on the control quality can be expected. Such a malfunction of the control loop, which is caused by the nonobservance of the limitation of the actuating variable during controller design, is called Reset-Windup or IntegralWindup effect in the literature [Ortseifen 2012]. To counteract the described misbehaviour of a Reset Windup, the structural extension of the control loop - an Anti-Reset Windup - is useful. A practical solution is an Anti-Reset Windup by back calculation [Hippe 2006], whereby a structural change is made in the controller.

\subsection{Distribution of limited, jointly-used actuating variable}

The handling of several control loops with a limited, jointly used actuating variable is a particularly challenging application [Lunze, 2016]. In this case, the available actuating variable is often distributed according to the principle "first come, first serve". This variant is referred to as "static limitation of the actuating variable" [Hellmich 2018]. An alternative to this described limitation is to link the control loops with each other and to exchange information about the required actuating variable. Fig. 2 shows this "harmonized limitation of the actuating variable". The aim of this distribution of the actuating variable (DOAV) is a harmonized consumption for each control loop. The actuating variables required by the controller are weighted relatively to each other and the available actuating variable is distributed in the actuator according to these weighting factors [Hellmich 2018].

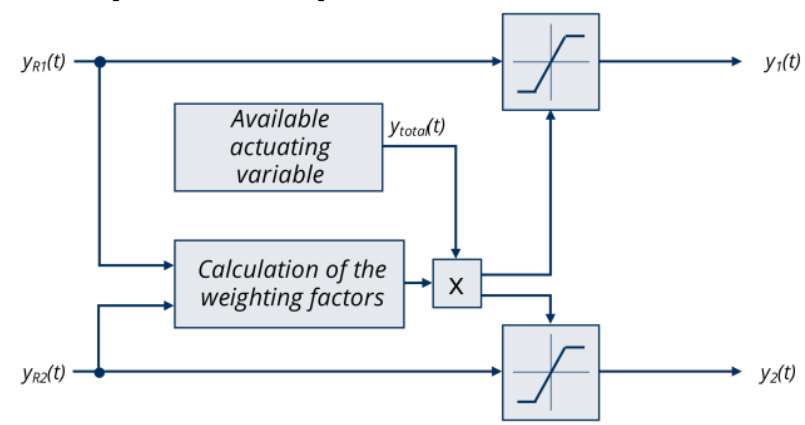

Fig. 2 : Scheme of the harmonized limitation of the actuating variable [Hellmich 2018]

\section{MOTIVATION AND SCOPE OF THE PAPER}

The state of the art shows a possible improvement of the thermal behaviour and in particular a reduction of deviations by integrated cooling mechanisms. There is also potential for higher energy efficiency of (fluidic) components. These potentials have not yet been integrated and investigated in a holistic design approach. The transfer project "Efficient temperature control of machine tool frame structures" of the CRC/TR 96 investigates this solution approach. 


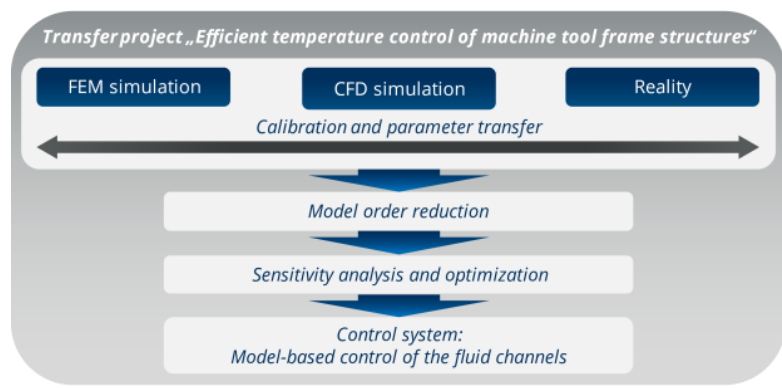

Fig. 3 : Procedure for efficient temperature control of machine tool frame structure

The aim is the thermo-energetic optimization of the temperature control circuits in the machine frame made of high-performance concrete (HPC) by securing and improving the thermal stability [Ihlenfeldt 2016]. Fig. 3 illustrates the course of action of the project.

The investigated machine frame including fluid channels is modelled by FEM with an integrated CFD simulation and subsequently validated by measurement data. In order to minimize the simulation times, the order of the validated model is reduced by a model order reduction (MOR). In addition to the model of the frame structure, the fluid-air cooling system used is mapped virtually. The goal of the overall simulation is a holistic network model, consisting of the reduced model of the frame structure and the fluid-aircooling system model, which enables shorter simulation times and the extension to transient boundary conditions and real processes, and still provides sufficiently good simulation results [Weber 2018]. This model enables for variant analysis and model-based development. The temperature control forms the superordinate control loop of the network model. Thus, it controls the temperature behaviour as a function of time based on simulations of the machine frame and the control system of the fluid temperature [Hellmich 2018].

The demand-oriented and energy-efficient control of the temperature of machine components is a current research focus. The established state of the art for cooling systems is a two-point controller, which cannot be regarded as optimal for the requirements of a temperature control. Therefore, two other control concepts, a single-loop and a multi-loop control, are examined below. A single-loop control is a common control strategy for machine tools, e.g. for axis control, and offers potentials to the efficiency of cooling systems. However, machine components represent MIMO systems whose cross-couplings has to be taken into account. This is possible by designing a multi-loop control, but such a control strategy has not yet been used for a temperature control. Therefore, it is important to find out whether a multi-loop control has a positive influence on the accuracy of a temperature control.

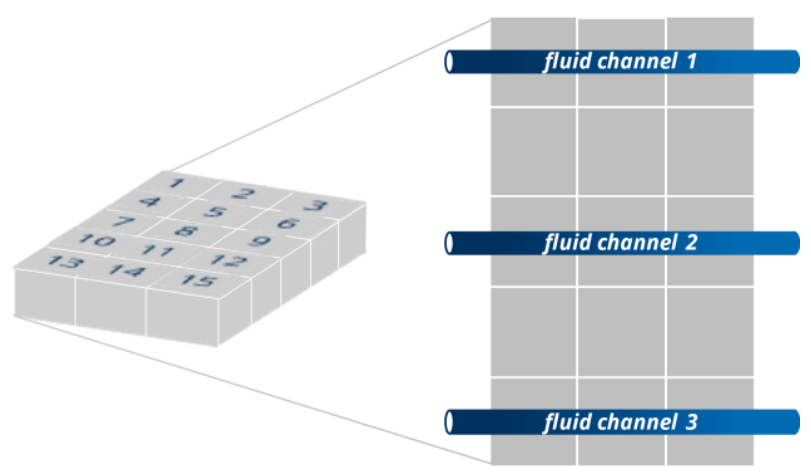

Fig. 4 : Simplified model of the frame structure
To reach the superordinate goal the following main research aspects are necessary:

- Conception of a methodology for the design of such a control strategy

- Design and dimensioning of an appropriate control strategy taking into account the methodology

- Validation of the control strategies taking into account varying test set-ups

- Derivation of general recommended actions for the design of a temperature control system

In order to evaluate more easily the functionality of the methodology and the benefit of the different control strategies, a simplified model of the machine frame is used. This simplified model divides into 15 elements of equal size and volume. Fig. 4 shows the arrangement of the three fluid channels in the simplified frame. The simplified model of the machine tool frame structure considers the heat conduction between the single elements, the heat conduction from fluid channel to machine frame, the effects of external heat loads on the elements, and the convection to the environment.

\section{COURSE OF ACTION}

This chapter considers the design and implementation of the two different control strategies. For both, the single-loop control as well as for the multi-loop control, the following methodical procedure is applied:

1. Identification of the controlled system,

2. Design of the controllers,

3. Investigation of the control strategy,

4. Evaluation of the results.

The following chapters are organized according to this methodology and each step is performed for the single-loop and the multi-loop control.

\subsection{Identification of the controlled system}

\section{Single-loop control}

The determination of characteristics of the model is a description of the transmission behaviour of the controlled systems [Bohn 2016]. For this purpose, the following three simulations are performed on the machine frame model (Fig. 5), which is a simplified variant of Fig. 13.

The experiment design is carried out in analogy to the set point jump of classical control engineering. The limitations of the model follow the real physical conditions and therewith, only allow the cooling of the elements. In order to counteract this, all elements of the frame are heated up homogeneously with $10 \mathrm{~W}$ per element for $30000 \mathrm{~s}$ to reach a static final value. Subsequently, the individual sections are charged with $7 \mathrm{~W}$ cooling capacity for identification. For the design of the Single-loop control, the controlled system is regarded as three individual single-input-single-output (SISO) systems.

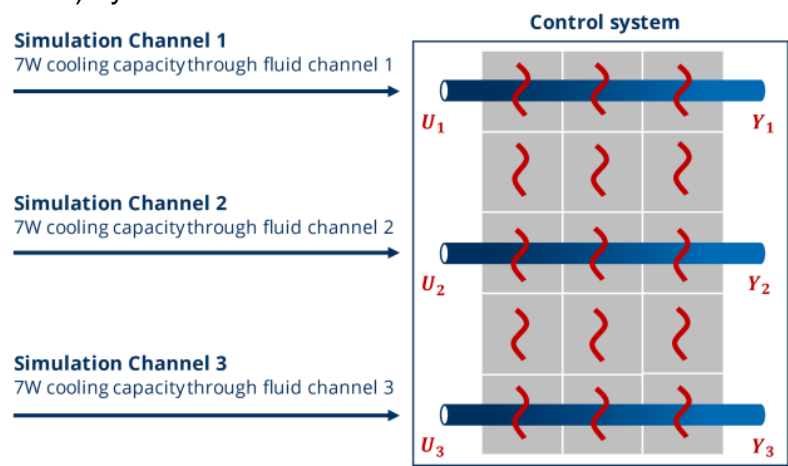

Fig. 5 : Experiments for Identification of the controlled system

MM Science Journal | 2021 | Special Issue on ICTIMT2021 
In order to determine the system parameters, the actual temperature value of the specific frame section is considered that corresponds with the applied step of the input variable. Identification is carried out based on the step response curves, whereas a lag element of unknown order $\left(P T_{n}\right)$ is assumed and the time percentage coefficient method according to [Schwarze 1962] are applied. For all three control sections, the order was found to be one, so they are proportional elements of first order $\left(P T_{1}\right)$. The identification equations according to Eq. (1) and (2) are used to calculate the proportional gain $K_{P}$ and the time constant $T_{1}$ [Lutz, 2003].

$K_{P}=\frac{x_{a}(t \rightarrow \infty)}{x_{e}}$

$T_{1}=\frac{x_{a}(t \rightarrow \infty)}{\dot{x}_{a}(t=0)}$

The controlled sections of the simplified model of the machine frame can now be described by the transfer functions according to Eq. (3) - (5).

$$
\begin{aligned}
& G_{1}(s)=\frac{U_{1}(s)}{Y_{1}(s)}=\frac{-0.1326}{1+s \cdot 1643.7} \\
& G_{2}(s)=\frac{U_{2}(s)}{Y_{2}(s)}=\frac{-0.1173}{1+s \cdot 2254.4} \\
& G_{3}(s)=\frac{U_{3}(s)}{Y_{3}(s)}=\frac{-0.1326}{1+s \cdot 1643.7}
\end{aligned}
$$

The transfer functions show that the controlled sections 1 and 3 , the external cooling circuits, have identical transfer behaviour, which is plausible due to the simplified machine frame model. The difference between (3) and (4) can be explained by the different influence of the neighbouring machine frame elements. However, it is important to carry out this step in order to prepare the methodology for future utilization. Due to the convection of the frame elements among themselves and the environment, the middle controlled circuit shows a deviating transfer behaviour.

\section{Multi-loop control}

In order to determine the characteristics for a multi-loop model, the couplings of the individual control circuits must be taken into account additionally. For this purpose, it is appropriate to represent the transfer behaviour of the controlled system in the form of a transfer matrix.

Based on the same simulations to identify the controlled system (Fig. 5) the evaluation of the results is different. In case of a MIMO system, all three outputs are considered for each experiment and the transfer behaviour of these outputs is described. The following $3 \times 3$-transfer matrix shows the results.

$$
G(s)=\left(\begin{array}{lll}
G_{11}(s) & G_{12}(s) & G_{13}(s) \\
G_{21}(s) & G_{22}(s) & G_{23}(s) \\
G_{31}(s) & G_{32}(s) & G_{33}(s)
\end{array}\right)
$$

The transfer functions of the three main control loops are located on the main diagonal of the matrix $\left(G_{11}, G_{22}, G_{33}\right)$; the remaining elements of the transfer matrix represent the transfer behaviours of the coupling sections. As with singleloop control, the time percentage method according to [Schwarze 1962] is used to identify the system parameters.

The time constant $T_{1}$ is averaged from the time percentage coefficients of the step response and the tabulated time percentage coefficients of the model step function for order $n$ (Eq. (6)) [Schwarze 1962].

$T_{1}=\frac{1}{3} \cdot\left[\frac{t_{10}}{\tau_{10}}+\frac{t_{50}}{\tau_{50}}+\frac{t_{90}}{\tau_{90}}\right]$
As in the case of single-loop control, the three main control circuits are of first order, i. e. they are first order proportional elements. Therefore, the determination of the time constant $T_{1}$ is done in the same way as for single-loop control, which explains the identical results. The proportional gain $K_{P}$ is calculated according to Eq. (1). The following transfer matrix derives from the results of the identification of the controlled system:

$G(s)=\left(\begin{array}{ccc}\frac{-0.1326}{1+s \cdot 1643.7} & \frac{-0.0662}{(1+s \cdot 1676.7)^{2}} & \frac{-0.0374}{(1+s \cdot 1540.3)^{3}} \\ \frac{-0.0662}{(1+s \cdot 1676.7)^{2}} & \frac{-0.1173}{1+s \cdot 2254.4} & \frac{-0.0662}{(1+s \cdot 1676.7)^{2}} \\ \frac{-0.0374}{(1+s \cdot 1540.3)^{3}} & \frac{-0.0662}{(1+s \cdot 1676.7)^{2}} & \frac{-0.1326}{1+s \cdot 1643.7}\end{array}\right)$

To validate the model accuracy of (7), the temperature time behaviours of the simplified machine frame are compared with the system output of (7) with identical input time series (taken from the identification experiments). To do this, (7) was re-modelled as a decoupled controlled system in pcanonical form [Zacher 2017]. Both outputs are compared by the correlation coefficient according to Eq. (8) [Darvishi 10] and show 0.9898 , which indicates very good model accuracy.

$\Delta n_{\ddot{A}}=\frac{\sum_{i=1}^{l}\left(\left(n_{\text {ist }}(i)-E\left(n_{\text {ist }}\right)\right) \cdot\left(n_{\text {model }}(i)-E\left(n_{\text {model }}\right)\right)\right)}{\sqrt{\sum_{i=1}^{l}\left(\left(n_{\text {ist }}(i)-E\left(n_{\text {ist }}\right)\right)^{2}\right) \cdot \sum_{i=1}^{l}\left(\left(n_{\text {model }}(i)-E\left(n_{\text {model }}\right)\right)^{2}\right)}}$

This step serves as validation for the identification procedure and is a requirement for moving along to the subsequent step of the methodology. With the addition of the graphical evaluation, the occurring deviations between the real and re-modelled controlled system can be assessed as very slight and the transfer matrix as sufficiently accurate for the further procedure. However, the deviations also indicate that no ideal behaviour of a $P T_{n}-$ element occurs and that the assumption of such an element does not completely satisfy the transfer behaviour of the model.

\subsection{Design of the controllers}

\section{Single-loop control}

Based on the identified parameters of the controlled system, the design of the controllers of the three single-loop control circuits uses the following various tuning rules:

(1) Amplitude optimum

(2) Symmetrical optimum

(3) Chien, Hrones, Reswick ( $0 \%$ overshoot)

(4) Chien, Hrones, Reswick (20\% overshoot)

(5) Ziegler and Nichols [Lutz 2003]

All of these optimization criteria theoretically require the design of a pure I-controller, since the identification approximates the controlled systems as first order proportional elements. Such a control law, however, leads to a slow control behaviour. In addition, it can be assumed that the simplified model of a machine frame does not exhibit ideal behaviour despite identification as a $P T_{1}-$ element (see section 4.1). For these reasons, the chosen approach is a $\mathrm{PI}$ control law. The transfer function of a $P T_{1}$ controlled system is defined with a delay time constant $T_{1}$.

However, to design a PI control law, a transfer behaviour with two time constants is necessary. Therefore, additional assumptions must be made for the second time constant. It is assumed that the second time constant is very small compared to the delay time constant $T_{1}$.

Therefore, the smallest possible sampling time $\left(t_{\text {tast }}=0.1 \mathrm{~s}\right)$ of the discrete simulation is used for this second time constant. For the controllers of the single-loop control the parameters are calculated according to table 1. 
Table 1 : Calculated parameters of the single-loop controllers

\begin{tabular}{lcccccc}
\hline $\begin{array}{l}\text { Tuning } \\
\text { rule }\end{array}$ & \multicolumn{3}{c}{$\begin{array}{c}\text { Proportional coefficient } \\
\mathbf{K}_{\mathbf{R}}[\mathrm{K} / \mathrm{W}]\end{array}$} & \multicolumn{3}{c}{$\begin{array}{c}\text { Reset time } \\
\mathbf{T}_{\mathbf{N}}[\mathbf{s}]\end{array}$} \\
\hline & $K_{R 1}$ & $K_{R 2}$ & $K_{R 3}$ & $T_{N 1}$ & $T_{N 2}$ & $T_{N 3}$ \\
$\mathbf{( 1 )}$ & 61,977 & 96,075 & 61,9177 & 1,643 & 2,254 & 1,643 \\
$\mathbf{( 2 )}$ & 61,977 & 96,075 & 61,9177 & 0.4 & 0.4 & 0.4 \\
$\mathbf{( 3 )}$ & 26,254 & 26,256 & 26,254 & 1,193 & 1,056 & 1,193 \\
$\mathbf{( 4 )}$ & 45,010 & 45,012 & 45,010 & 994 & 880 & 994 \\
$\mathbf{( 5 )}$ & 111,563 & 172,971 & 111,563 & 0.3 & 0.3 & 0.3 \\
\hline
\end{tabular}

Multi-loop control

For the temperature control of the machine tool frame structure, a multi-loop control by means of decoupling with a controller network in v-canonical form (Fig. 6) is aimed at.

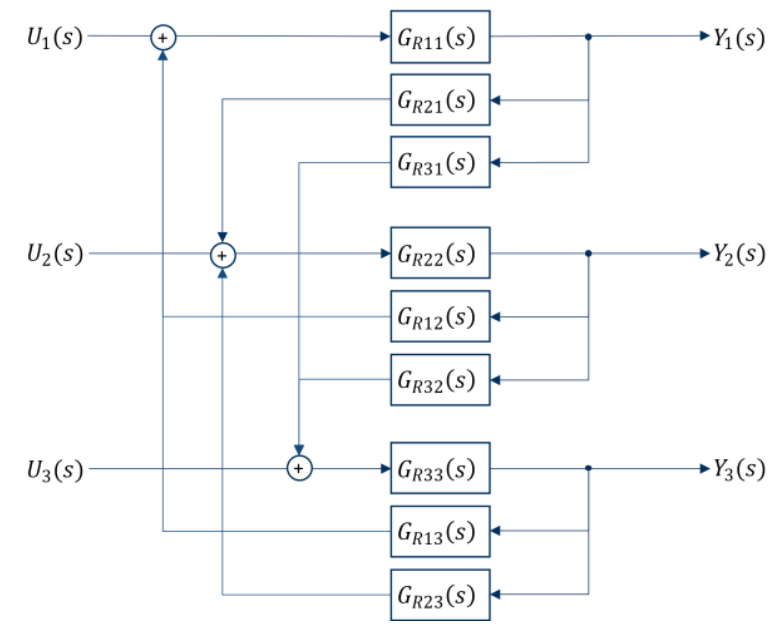

Fig. 6 : Controller network in v-canonical form [Zacher 2017]

This is a descriptive and easy to understand method of a multi-loop control, but represents an additional effort compared to a single-loop control. The design of the three main controllers and six decoupling controllers is based on the three main control loops and six coupling loops. Since the transmission behaviour of the main control loops of the multi-loop control and the control loops of the single-loop control are identical, the results for single-loop controllers are also identical with the three main controllers of the multiloop control. The transmission behaviour of the decoupling controllers is being calculated according to [Zacher 2017] with the following Eq.:

$$
\begin{aligned}
& G_{R 12}(s)=\frac{G_{12}(s)}{G_{11}(s)}=\frac{0.0662+s \cdot 108.8}{0.1326+s \cdot 477.7+s^{2} \cdot 372800} \\
& G_{R 21}(s)=\frac{G_{21}(s)}{G_{22}(s)}=\frac{0.0662+s \cdot 149.2}{0.1173+s \cdot 393.4+s^{2} \cdot 329800} \\
& G_{R 13}(s)=\frac{G_{13}(s)}{G_{11}(s)}=\frac{0.0374+s \cdot 61.47}{0.1326+s \cdot 612.8+s^{2} \cdot 94 \cdot 10^{4}+s^{3} \cdot 48 \cdot 10^{7}} \\
& G_{R 31}(s)=\frac{G_{31}(s)}{G_{33}(s)}=\frac{0.0374+s \cdot 61.47}{0.1326+s \cdot 612.8+s^{2} \cdot 94 \cdot 10^{4}+s^{3} \cdot 48 \cdot 10^{7}} \\
& G_{R 23}(s)=\frac{G_{23}(s)}{G_{22}(s)}=\frac{0.0662+s \cdot 149.2}{0.1173+s \cdot 393.4+s^{2} \cdot 329800} \\
& G_{R 32}(s)=\frac{G_{32}(s)}{G_{33}(s)}=\frac{0.0662+s \cdot 108.8}{0.1326+s \cdot 477.7+s^{2} \cdot 372800}
\end{aligned}
$$

The complete controller network of the multi-loop control, consisting of the designed single-loop controllers (see table 1) combined with the decoupling controllers (according to Eq. (9) to (14)), is implemented and examined in Matlab/Simulink ${ }^{\odot}$.

\subsection{Evaluation of the control strategy}

For the model of the machine frame, investigations with various test set-ups take place. Only by variation of these conditions a broad analysis of the control approaches with reference to practical applications is possible, in order to derive generally valid recommendations for action.

\section{Varying test set-ups}

The chosen varying bounding conditions for the experimental investigations are

\section{- Exposure scenarios (ES) and}

- $\quad$ Schemes of the effective thermal loads (SETL).

The real HPC machine frame, investigated in the CRC transfer project, forms the basis for a machine tool. Hence, a cutting process was chosen as role model for investigation. To meet the reduced complexity of the machine frame (Fig. 4), the assumptions to represent the process in terms of ES were also simplified. Preliminary investigations by the $\mathrm{CRC} / \mathrm{TR} 96$ show that a significant amount of the heat exposure of a spindle is transferred to the frame structure of a machine tool. Hence, one fluid channel represents this heat input and one element in the model is loaded with $250 \mathrm{~W}$ (for ES 1) or respectively with $150 \mathrm{~W}$ (for ES 2). The two other fluid channels represent cooling systems of feed drives. Therefore, the external heat exposure acts on all elements of the respective cooling channel with $25 \mathrm{~W}$ (ES 1) or respectively $50 \mathrm{~W}$ (ES 2). Inspired by typical machining processes, a combination of roughing, Fig. 7-(1), semi-finishing, Fig. 7-(2), and finishing, Fig. 7-(3), is assumed. Hence, a cycle with three processing steps of 60 minutes and decreasing exposure intensity/thermal load was defined. After machining, a machine set-up process is typically necessary. Therefore, a 60 minute machine standstill is included, Fig. 7-(4), where no external heat loads are present.

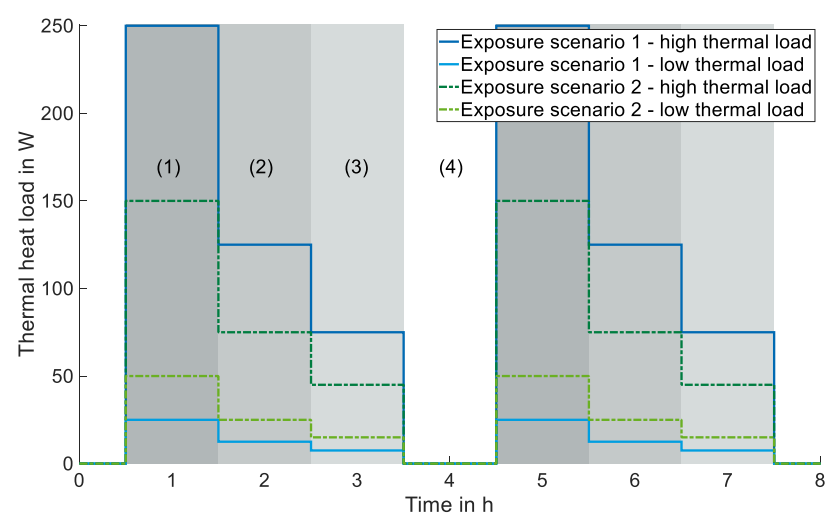

Fig. 7 : Thermal loads of exposure scenario 1 and 2

Two ES were designed; scenario 1 shows a high gradient between the maximum heat exposure of the spindle and the heat exposure of the feed drives, whereas this gradient is low for ES 2 (see Fig. 8). For the comparison of the different limitations of the actuating variable, a differentiation in the selection of the points of application of the effective thermal loads is made. Fig. 8 shows the two designed schemes of the effective thermal loads. For scheme 1 the heat exposure caused by the spindle acts on element 2 in the simplified simulation model, this means in the middle of the upper fluid channel. 

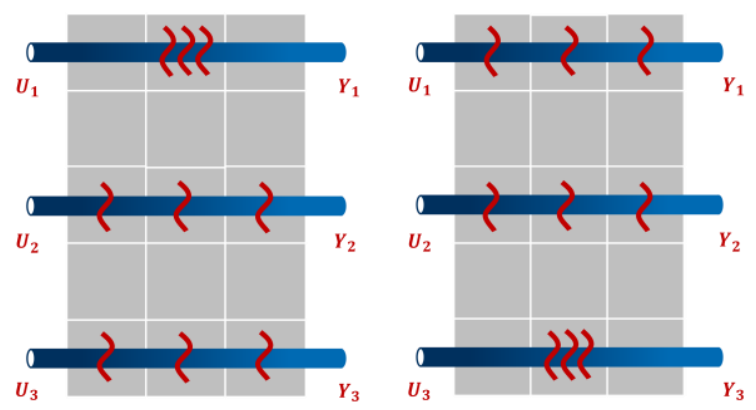

Fig. 8 : SETL 1 (left) and SETL 2 (right)

For scheme 2 this heat exposure acts on element 14, this means in the middle of the lower fluid channel. It can be concluded that for scheme 1 , the control circuit with a large coolant requirement is at the beginning of the "supply chain", for scheme 2 at the end of it. The elements of the other two fluid channels are each subjected to the heat exposure of the feed drives.

Results of the simulation comparing single- and multi-loop control

To validate the performance of the two control strategies, simulations were performed with both exposure scenarios in combination with both schemes of the effective thermal loads. For the evaluation of the results, the integral of absolute error (IAE) [Schulz 2015] was calculated as quality criterion. This was used for the determination of the deviations $I A E_{\text {setpoint }}$ to the set point temperature $T_{\text {setpoint }}$ according to Eq. (15). For an optimal feedforward setpoint control strategy, this quality criterion must be minimized.

$$
I A E_{\text {setpoint }}=\sum_{i=1}^{3} \int_{0}^{\infty}\left|x_{a i}(t)-T_{\text {setpoint }}\right| d t
$$

Eq. (16) is used to calculate the deviations of the temperature curves among each other (IAEgradient). To reduce the temperature gradients IAEgradient must be minimized.

$I A E_{\text {gradient }}=\sum_{i=1}^{3} \sum_{j=i+1}^{3} \int_{0}^{\infty}\left|x_{a i}(t)-x_{a j}(t)\right| d t$

Fig. 9 and 10 show the results of the single-loop control for exposure scenario 2 with both schemes of the effective thermal loads. Fig. 9 shows them in combination with a static distribution of the actuating variable, Fig. 10 with a harmonized distribution. Based on the calculated IAE setpoint and $I A E_{\text {gradient }}$ (see Table 2), it can be seen that the singleloop control operates with identical control accuracy by using a harmonized distribution of the actuating variable, independent of the scheme of the effective thermal loads. From this, it can be concluded that the temperature regime of the machine tool frame structure becomes independent of the occurrence of the thermal loads. If the knowledge gained from this control strategy is adapted to other

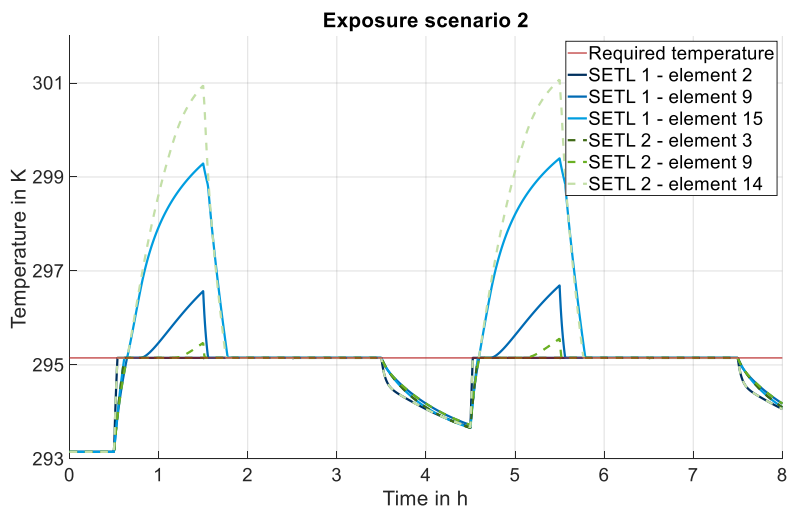

Fig. 9 : Temperature curves of the single-loop control with static distribution of actuating variable machine components or to the entirety of a machine tool, great potential for a more flexible, thermally stable individual part production becomes apparent. Thus, a harmonized limitation of the actuating variable can react more efficiently to thermal problems caused by varying load collectives acting on the machine than currently applied temperature controls. For the demonstrated application, the results (see table 2 ) show an improvement by $32.4 \%$ of the sum of $I A E_{\text {setpoint }}$ and IAE gradient for SETL 1 and ES 2. The application of the presented distribution of actuating variable is not required for machines in series production, as thermal problems can already be reduced to a minimum during the hydraulic design of the fluid system by taking into account the occurring effective thermal loads.

Table 2 : Results of the quality criteria of the single-loop control for exposure scenario 2

\begin{tabular}{ccccc}
\hline SETL & DOAV & $\begin{array}{c}\text { Tuning } \\
\text { rule }\end{array}$ & IAE $_{\text {setpoint }}$ & IAE $_{\text {gradient }}$ \\
\hline $\mathbf{1}$ & static & 5 & 123,457 & 120,408 \\
$\mathbf{2}$ & static & 5 & 129,786 & 152,072 \\
$\mathbf{1}$ & harmonized & 2 & 126,099 & 38,823 \\
$\mathbf{2}$ & harmonized & 2 & 126,099 & 38,823 \\
\hline
\end{tabular}

Based on Fig. 11 and 12, the two control strategies are investigated, single-loop control (Fig. 11) and multi-loop control (Fig. 12) will be compared. The simulation results show that the use of a multi-loop control system achieves a higher control quality with regard to a homogeneous temperature field (Table $3-I A E_{\text {gradient }}$ ) within the machine tool frame structure. By minimizing the temperature gradient, however, global deviations from the actual value to the setpoint (Table $3-I A E_{\text {setpoint }}$ ) occur, which causes a holistic heating of the structure.

Table 3 : Results of the quality criteria for exposure scenario 2 with harmonized DOAV

\begin{tabular}{ccccc}
\hline SETL & $\begin{array}{c}\text { Control } \\
\text { strategy }\end{array}$ & $\begin{array}{c}\text { Tuning } \\
\text { rule }\end{array}$ & IAE $_{\text {setpoint }}$ & IAE $_{\text {gradient }}$ \\
\hline $\mathbf{2}$ & single-loop & 2 & 126,099 & 38,823 \\
$\mathbf{2}$ & multi-loop & 5 & 136,826 & 32,116 \\
\hline
\end{tabular}

In contrast, single-loop control pursues the goal of a strict setpoint sequence, which means that the global deviations from the setpoint temperature are smaller than with multiloop control. In the simulation results, in which the multiloop control for exposure scenario 1 was investigated, the use of the harmonized distribution of the actuating variable (Fig. 14), contrary to expectations, does not show positive effects on the control quality.

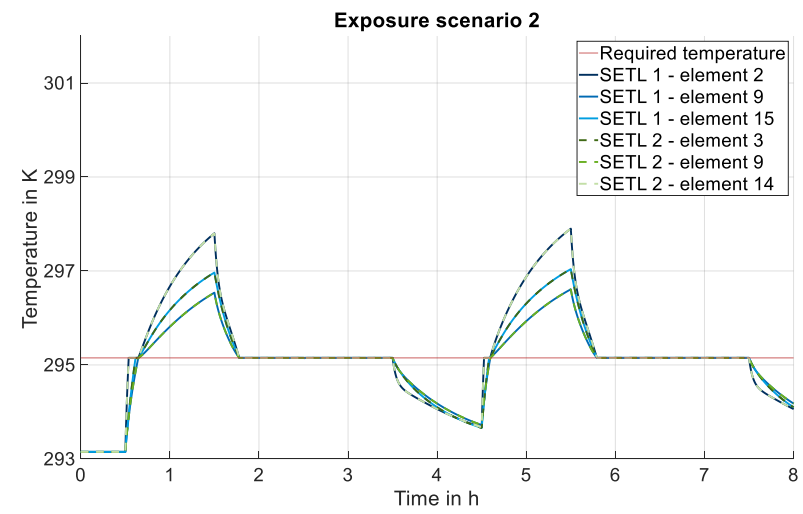

Fig. 10 : Temperature curves of the single-loop control with harmonized distribution of actuating variable 


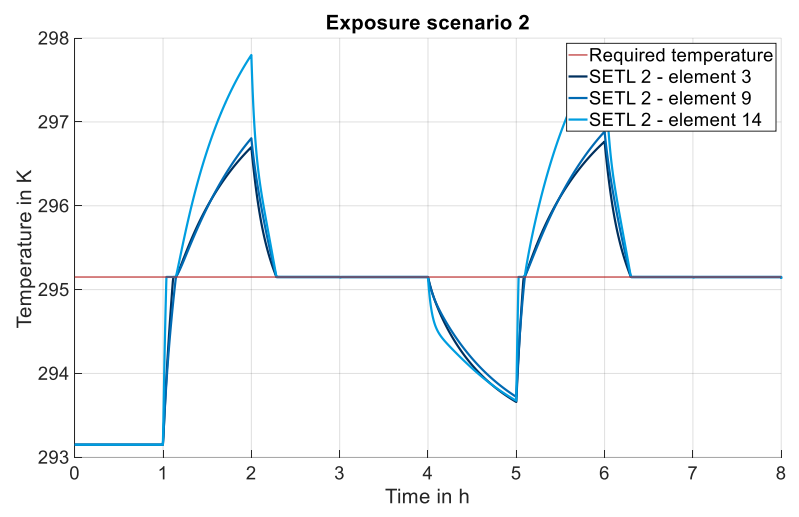

Fig. 11 :Temperature curves of the single-loop control with harmonized distribution of actuating variable

In comparison to a static control value restriction (Fig. 13), both the control performance with respect to the setpoint value and the control performance with respect to a homogeneous temperature field deteriorate (see Table 4).

Table 4 : Results of the quality criteria of the multi-loop control for exposure scenario 1

\begin{tabular}{ccccc}
\hline SETL & DOAV & $\begin{array}{c}\text { Tuning } \\
\text { rule }\end{array}$ & IAE $_{\text {setpoint }}$ & IAE $_{\text {gradient }}$ \\
\hline $\mathbf{2}$ & static & 5 & 149,624 & 111,415 \\
$\mathbf{2}$ & harmonized & 4 & 172,445 & 125,946 \\
\hline
\end{tabular}

\section{CONCLUSION AND OUTLOOK}

Industry 4.0 requires highly efficient production in manufacturing. Basically, this results in demands for high precision, low machining times and low costs, both for the process and for the machine tool. Combined with the demand for flexibility and batch size 1 , the minimisation of the temperature gradients associated with the control of the temperature field enables highly precise and adaptive production. This involved the design and investigation of several control strategies for a demand-oriented temperature control for the given use case. The application case includes the problem of the limited and jointly used actuating variable as well as that of the coupled controlled system. A decentralized single-loop control and a multi-loop control by decoupling were designed, investigated and compared, whereby both strategies were investigated with a static and harmonized distribution of actuating variable for varying test set-ups. The objective was to create the basis for a transferable methodology for this research area.

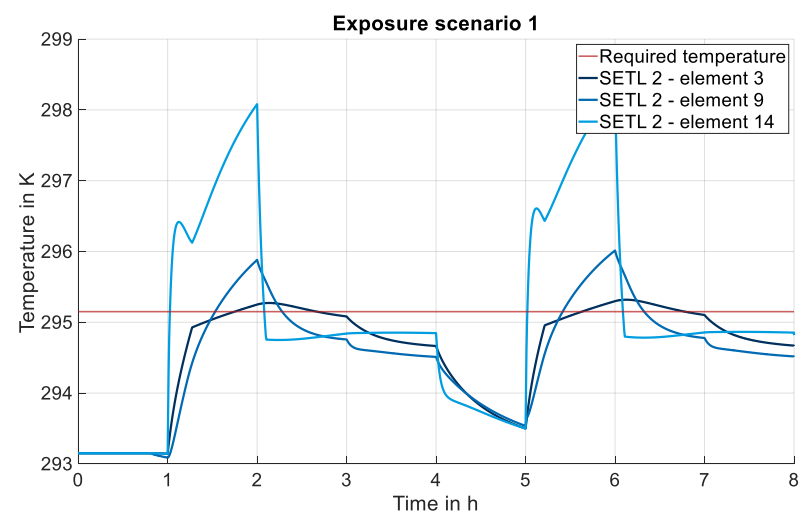

Fig. 14 : Temperature curves of the multi-loop control with static distribution of actuating variable

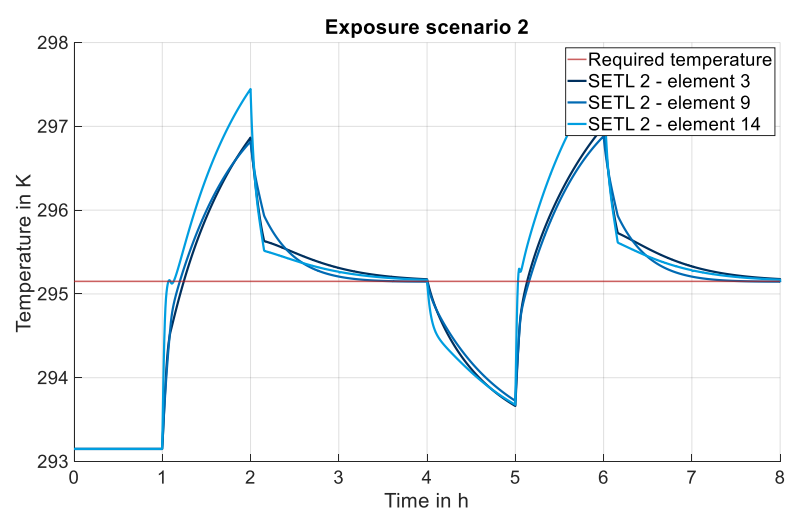

Fig. 12 : Temperature curves of the multi-loop control with harmonized distribution of actuating variable

It was possible to demonstrate the positive effects of changing the controller structures, but also by adjusting the limitation of the actuating variable. In particular, potentials to efficiently control the inhomogeneity of the temperature field of a machine tool are shown. The design of the control strategies shown here can be regarded as a methodology for more complex simulation models and practical applications for temperature control. The next step of development is the implementation of the temperature control at the Hydropol frame (see Fig. 15) with optimized cooling system and decentralized arrangement of the pumps.

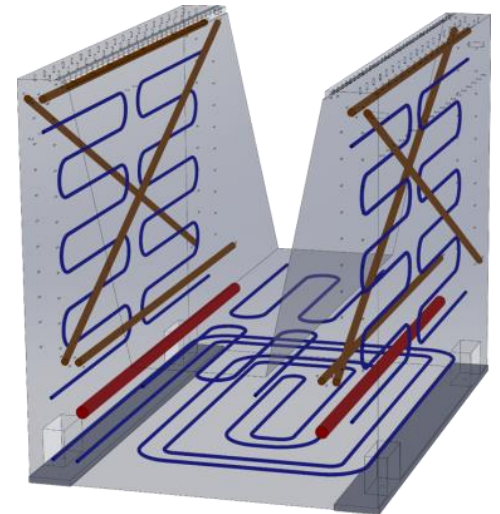

Fig. 13 : Hydropol machine tool frame

Therefore, the following steps have to be worked out:

- Adaptation of the developed methodology to new boundary conditions of the Hydropol frame

- Implementation of the adapted methodology in the PLC

- Execution and evaluation of measurement tests to examine the controller performance

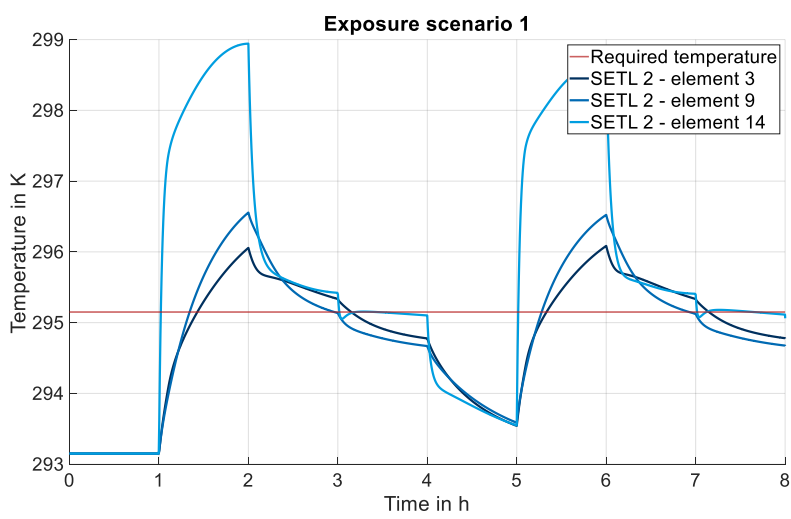

Fig. 15 : Temperature curves of the multi-loop control with harmonized distribution of actuating variable 
Such demand-based temperature control can also be relevant for other machine components and should therefore be investigated further. For highly complex MIMO systems, which have considerably more input and output variables than the simplified machine frame model, a prior critical estimation of the necessary effort for design is mandatory. In addition, considerations should be made here about further implementation possibilities of a multiloop control, since the clarity and traceability of a decoupling control for a high number of input and output variables is no longer given.

\section{REFERENCES}

\section{Books:}

[Brecher 2017] Brecher, C. and Weck, M. Werkzeugmaschinen Fertigungssysteme 2, Chapter: Thermo-elastisches Verhalten von Werkzeugmaschinen. Berlin: Springer Vieweg, 2017. ISBN 978-3-662-46566-0

[Bohn 2016] Bohn, C. and Unbehauen, H. Identifikation dynamischer Systeme Methoden zur experimentellen Modellbildung aus Messdaten. Wiesbaden: Springer Vieweg, 2016. ISBN 978-3-8348-1755-6

[Großmann 2015] Großmann, K. Thermo-energetic Design of Machine Tools. Cham: Springer International Publishing, 2016. ISBN 978-3-319-12624-1

[Hippe 2006] Hippe, P. Windup in Control Its Effects and Their Prevention. London: Springer, 2007. ISSN 1430-9491 [Lunze 2016] Lunze, J. Automatisierungstechnik: Methoden für die Überwachung und Steuerung kontinuierlicher und ereignisdiskreter Systeme. Berlin: De Gruyter Oldenbourg, 2016. ISBN 978-3-11-046557-0

[Lutz 2003] Lutz, H. and Wendt, W. Taschenbuch der Regelungstechnik. Frankfurt am Main: Verlag Harri Deutsch, 2003. ISBN 3-8171-1705-1

[Neugebauer 2013] Neugebauer, R. Handbuch Ressourcenorientierte Produktion. München: Hanser Verlag, 2013. ISBN 978-3-446-43008-2

[Schulz 2015] Schulz, G. Regelungstechnik 1: Lineare und nichtlineare Regelung, rechnergestützter Reglerentwurf. Muenchen: Oldenbourg Wissenschaftsverlag, 2010. ISBN 978-3-486-59194-1

[Zacher 2017] Zacher, S. and Reuter, M. Regelungstechnik fuer Ingenieure: Analyse, Simulation und Entwurf von Regelkreisen. Wiesbaden: Springer Vieweg, 2017. ISBN 978-3-658-17631-0

\section{Papers in a journal:}

[Augenstein 2012] Augenstein, E., et.al. Energieeffiziente Kuehlsysteme fuer Werkzeugmaschinen. Wt Werkstatttechnik online, 2012, Vol. 102, No. 5, pp 306-311. [Darvishi 2010] Darvishi, A. Translation Invariant Approach for Measuring Similarity of Signals. Journal of Advances in Computer Research, July 2010, Vol. 1, No. 1, pp 19-27. ISSN 2008-6148

[Liu 2019] Liu, K., et.al. Intelligentization of machine tools: comprehensive thermal error compensation of machineworkpiece system. The International Journal of Advanced Manufacturing Technology, March 2019, Vol. 102, pp 38653877.

[Mayr 2012] Mayr, J. et al: Thermal errors in machine tools. CIRP Annals, 2012, Vol. 61(2), p. 771-791

[Mori 2019] Mori, K., et.al. Energy efficiency improvement of machine tool spindle cooling system with on-off control, CIRP Journal of Manufacturing Science and Technology, May 2019, Vol. 25, pp 14-21. ISSN 1755-5817
[Putz 2018] Putz, M., et.al. Industrial consideration of thermal issues in machine tools. Production Engineering, 2018, Vol. 12, pp 723-736.

[Ramesh 2003] Ramesh, R., et.al. Thermal error measurement and modelling in machine tools. Part I. Influence of varying operating conditions. International Journal of Machine Tools and Manufacture, March 2003, Vol. 43, No. 4, pp 391-404. ISSN 0890-6955

[Schwarze 1962] Schwarze, G. Bestimmung der regelungstechnischen Kennwerte von P-Gliedern aus der Übergangsfunktion ohne Wendetangentenkonstruktion. Messen-Steuern-Regeln, 1962, Vol. 5, pp 447-449.

\section{Papers in proceedings:}

[Hellmich 2018] Hellmich, A., et.al. Analyzing and Optimizing the Fluidic Tempering of Machine Tool Frames, Conference on Thermal Issues in Machine Tools: Proceedings, Dresden, 2018.

[Ihlenfeldt 2017] Ihlenfeldt, S., et.al. Self-optimizing thermal correction, International Academy for Production Engineering, Paris, 2017.

[Regel 2018] Regel, J., et.al. Evaluation of thermoenergetic behavior for demand-oriented operating of machine tool cooling systems, Procedia Manufacturing, $15^{\text {th }}$ Global Conference on Sustainable Manufacturing, Haifa, 2018. Elsevier, pp 213-220, ISSN 2351-9789

[Smith 2009] Smith, S., et.al. Temperature control and machine dynamics in chip breaking using CNC toolpaths, CIRP Annals, Boston, August 2009, Vol. 58, No. 1, pp 97100. ISSN 0007-8506

[Weber 2018] Weber, J., et.al. Combined and fast computable thermal models for situationally optimal tempering of machine tool components. Procedia CIRP, 12th Conference on Intelligent Computation in Manufacturing Engineering, Neapel, July 2018. Elsevier, Vol. 79, pp 608-613. ISSN 2212-8271

[Wegener 2014] Wegener, K. Innovative Werkzeugmaschine - Praezision, Produktivitaet, Effizienz. Industrie 4.0 - die intelligente Fabrik der ZukunftTagungsband Wiener Produktionstechnik Kongress, 2014. ISBN 978-3903015005

\section{Technical reports or thesis:}

[Ess 2012] Ess, M. Simulation and compensation of thermal errors of machine tools. Diss. ETH No. 20300. Zürich: ETH Zürich, 2012

[Ihlenfeldt 2016] Ihlenfeldt, S. and Weber, J. Effiziente Gestelltemperierung. 2016.

[Ortseifen 2012] Ortseifen, A. Entwurf von modellbasierten Anti-Windup-Methoden fuer Systeme mit Stellbegrenzungen. Darmstadt: TU Darmstadt, Institut für Automatisierungstechnik und Mechatronik, 2012. ISBN 978-3-18-522508-6

\section{ACKNOWLEDGEMENTS \\ D) $\mathrm{G}$ Deutsche \\ Forschungsgemeinschaft}

The presented research activities are part of the transfer project "Robust and thermo-energetically optimal tempering of machine tool frames with fluidic tempering systems"(Ref. No. CRC/TR 96, T02). The authors would like to thank the German Research Foundation (DFG) and all project partners including HYDAC Cooling $\mathrm{GmbH}$, FRAMAG Industrieanlagenbau $\mathrm{GmbH}$ and METROM Mechatronische Werkzeugmaschinen $\mathrm{GmbH}$ for the financial support. 